\author{
ENGENHARIA ELÉTRICA
}

\title{
ALTERAÇÕES NA NR-10 E OS SERVIÇOS COM ELETRICIDADE1
}

\author{
CHANGES IN NR-10 AND SERVICES WITH ELECTRICITY
}

\author{
Lucas Rissi Duarte - lucasduarte081090@gmail.com \\ Prof. Cristiano Minotti - cminotti@uniara.edu.br \\ Uniara - Universidade de Araraquara -Araraquara -São Paulo -Brasil
}

\section{RESUMO}

A Norma Regulamentadora no 10 (NR-10), que trata de segurança e prevenção de acidentes em instalações elétricas, sofreu muitas alterações em seu texto no ano de 2004, isso fez com que empresas e prestadores de serviços se adequassem às novas regras. No entanto, muitos trabalhadores não fazem a correta aplicação das diretrizes, muitas vezes motivados pela dificuldade de compreensão do texto. Assim, este trabalho identificou as mudanças ocorridas no texto e, como resultado, é apresentado um check-list que visa facilitar o trabalho em instalações elétricas.

Palavras-chave: Norma Regulamentadora № 10. Instalações Elétricas. Segurança no trabalho. Segurança em Instalações Elétricas. Roteiro de Trabalho.

\begin{abstract}
The Regulatory Norm No. 10 (NR-10), which comes to safety and accident prevention in electrical installations, has undergone many changes in its text in 2004, this has meant enterprises and service providers to conform to the new rules. However, many workers do not make the correct application of the guidelines, often motivated by the difficulty of understanding the text. This work has identified the changes in the text and as a result, a checklist is presented to facilitate the work in electrical installations.
\end{abstract}

Keywords: Regulatory Standard №. 10. Electrical Installations. Safety at work. Working Script. Safety in Electrical Installations.

\footnotetext{
${ }^{1}$ Graduando no Curso Bacharelado de Engenharia Elétrica - Lucas Rissi Duarte.

${ }^{2}$ Orientador(a) Docente do curso Engenharia Elétrica - Cristiano Minotti
} 


\section{INTRODUÇÃO}

Dados do Ministério da Previdência Social (MPS) mostram que entre 2018 e 2020 ocorreram quase 1 milhão de acidentes de trabalho no Brasil, dos quais mais de 350 mil geraram afastamento superior a 15 dias e quase 5 mil mortes, média de 40 trabalhadores por dia faleceram ou ficaram inválidos. (PREVIDENCIA, 2021)

Dentre os principais tipos de acidentes destacam-se:

1) quedas, ocorrem em virtude de pisos elevados, molhados, lisos e rampas;

2) uso de ferramentas, muitas vezes o trabalhador executa suas atividades com ferramentas que exercem algum tipo de perigo;

3) lesões por esforço repetitivo, quando o trabalhador executa atividades repetitivas por longos períodos de tempo e causa danos à musculatura do membro;

4) choques elétricos, causam queimaduras e danos ao coração de forma intensa (SENAI, 2021).

Esses números, que a cada ano assustam a sociedade e geram elevados custos para as empresas e para o INSS, podem e devem ser reduzidos, pois nos dias atuais existem tecnologias que contribuem por meio de técnicas e ações especificas, para a redução dos acidentes. (PREVIDENCIA, 2021)

Alguns dos principais fatores que contribuem para a ocorrência de acidentes são: a alta rotatividade da mão de obra, falta de qualificação e/ou treinamento de segurança e ausência de uma cultura de utilização correta dos Equipamentos de Proteção Individual (EPI) (BARROS, 2020).

No exercício de suas atividades, o trabalhador do setor elétrico está exposto a um grande número de acidentes, que podem ocorrer caso não sejam tomadas as devidas providencias. Para isso foram instituídas normas e regras que regulamentam as atividades com redes e instalações elétricas. (NORMAS, 2021)

De acordo com Lobão e Lourenço (2017), a principal é a Norma Regulamentadora ํ․ 10 -NR-10, que tem por objetivo o estabelecimento de diretrizes de trabalho que garantam o controle dos riscos, previnam acidentes e, assim, garantam a segurança dos trabalhadores, e de terceiros, envolvidos em serviços com eletricidade. (NORMAS, 2021)

Este trabalho tem sua importância ligada à necessidade cada vez maior, de se manter um ambiente de trabalho seguro por meio do cumprimento das regras colocadas pela legislação. Além disso, é uma forma de garantir a redução de custos 
para as empresas, uma vez que os acidentes oneram sobremaneira os resultados financeiros bem como podem manchar a imagem da marca.

\subsection{Objetivo geral}

O objetivo geral deste trabalho é desenvolver um modelo de trabalho para prestação de serviços em redes e instalações elétricas que siga os padrões estabelecidos pela NR-10 e contribua para a redução dos riscos.

\subsection{Objetivos específicos}

- Identificar problemas da prestação de serviços de energia elétrica, bem como os riscos provenientes das atividades em redes elétricas.

- Identificar as mudanças propostas no novo texto da norma.

- Verificar como a nova NR-10 é utilizada para a execução dos trabalhos e como as empresas têm se adaptado às mudanças sugeridas pela norma e como ela influência nas atividades dos trabalhadores.

- Estabelecer um modelo de trabalho baseado na NR-10 que contribua para a minimização dos riscos.

\section{REVISÃO BIBLIOGRÁFICA}

Para muitos autores (LOBÃO, LOURENÇO, 2017; ZOCCHIO, 2016; FERNANDES, 2017), a segurança no trabalho caracteriza-se pela prevenção de riscos e de acidentes nas atividades de trabalho visando à defesa da integridade do trabalhador. Trata-se de um conjunto de ciências e tecnologias que buscam a proteção do funcionário ou trabalhador em seu local de trabalho, no tocante à questão da segurança e da higiene do trabalho.

Os riscos que surgem no trabalho, para Zocchio (2016) e Barros (2020), podem ser classificados em cinco grupos: físicos, biológicos, químicos, ergonômicos e mecânicos. Para efeito deste trabalho será dado enfoque nos riscos físicos, mais especificamente, os que são inerentes às atividades em instalações elétricas. 


\subsection{Energia Elétrica}

Conforme explica Nunes (2019), a energia elétrica pode causar sérios danos ao trabalhador, desde lesões até a morte, dependendo da intensidade da descarga. Para Lobão e Lourenço (2017), o risco elétrico é uma possibilidade de ocorrer danos às pessoas ou ao patrimônio, eles ocorrem a partir de uma condição perigosa.

Fernandes (2017) complementa ao dizer que em serviços elétricos, os trabalhadores se expõem a acidentes que têm consequências diretas e indiretas, tais como choque, arco elétrico, quedas, batidas, incêndio, explosões, queimaduras, etc.

\subsection{Riscos associados ao trabalho em energia elétrica}

Segundo Bonilha (2017) e Camisassa (2019), as condições de trabalho estão relacionadas ao ambiente em que o funcionário executa suas atividades, bem como aos equipamentos que ele utiliza. Uma forma de se preservar a saúde e integridade física do trabalhador é praticar os requisitos propostos pela NR-9, que estabelece o Plano de Prevenção de Riscos Ambientais - PPRA. Através dele é possível antecipar ocorrências de riscos ambientais, existentes ou que podem vir a existir.

Já para Dul e Weerdmeester (2020), no ambiente de trabalho o funcionário é exposto a quatro tipos de riscos: químicos, biológicos, físicos e ergonômicos. Os autores argumentam que para reduzir e/ou eliminar os possíveis problemas causados pelo ambiente de trabalho é preciso agir de três formas distintas:

1. Reduzir/eliminar os efeitos dos agentes prejudiciais.

2. Isolar pessoa ou fonte de risco.

3. Proteger individualmente usando EPI's.

Lourenco e Lobão (2018) e Nunes (2020) consideram que nas atividades relacionadas à energia elétrica, os trabalhadores estão expostos a riscos físicos, ou seja, ao choque elétrico, que se caracteriza pela passagem de uma corrente elétrica pelo corpo humano. Isso pode gerar contração muscular, paradas cardiorrespiratórias e queimaduras na pele.

$\mathrm{Na}$ maioria dos casos de acidentes evolvendo eletricidade as vítimas apresentam queimaduras porque a corrente elétrica atinge o organismo através do revestimento cutâneo. Devido à alta resistência da pele, a passagem da corrente elétrica produz alterações estruturais no organismo. As queimaduras provocadas pela 
eletricidade diferem daquelas causadas por efeitos químicos, térmicos e biológicos. (LOBAO, LOURENÇO, 2018; COPEL, 2017; MAHLE, 2018).

Acidentes de trabalho acontecem quando as atividades desenvolvidas expõem os trabalhadores a situações inseguras e perigosas. Para Campos et. al. (2020), os riscos de acidentes são resultado de uma probabilidade somada a uma consequência.

O primeiro passo para a eliminação dos riscos é fazer sua devida avaliação e identificação, em seguida, devem ser aplicadas medidas de segurança, que visam proteger os trabalhadores envolvidos, isolando, sinalizando e eliminando os riscos existentes. (ZOCCHIO, 2016; LOBAO, LOURENÇO, 2018; BONILHA, 2017).

Existem duas NR's que se relacionam à prevenção de acidentes de trabalho, a de $\mathrm{n}^{\circ} 5$ e a de ํㅜ 9. A primeira regulamenta a criação da Comissão Interna de Prevenção de Acidentes - CIPA, que tem por objetivo prevenir acidentes e doenças do trabalho, fazendo com que toda atividade não afete a preservação da vida e da saúde. (BRASIL, 2021).

Já a NR-9 cria o Programa de Prevenção de Riscos Ambientais - PPRA, que consiste em um projeto, criado pelas empresas, que previne acidentes por meio de atividades sistematizadas de antecipação, reconhecimento, avaliação e controle de todos os riscos ambientais. (BRASIL, 2021).

É de responsabilidade da CIPA a criação do Mapa de Riscos, que consiste na representação gráfica dos riscos existentes nos diversos ambientes de trabalho. $O$ mapeamento é feito nos locais de trabalho apontando os riscos que estão expostos ao trabalhador. (BRASIL, 1978; CAMPOS, 2019).

O objetivo do mapa é "reunir as informações necessárias para estabelecer o diagnóstico da situação de segurança e saúde no trabalho na empresa e possibilitar, durante a sua elaboração, a troca e divulgação de informações entre os trabalhadores, bem como estimular sua participação nas atividades de prevenção”. (BRASIL, 1994).

A figura 1 apresenta um exemplo de mapa de risco já estruturado e com todas as informações necessárias. Como pode ser visto, os círculos são utilizados para indicar a intensidade dos riscos, podendo ser grande, média ou pequena e as cores indicam o tipo de risco ao qual o trabalhador estará exposto ao desenvolver suas atividades no local. (CAMPOS, 2019; CASTRO, 2019). 


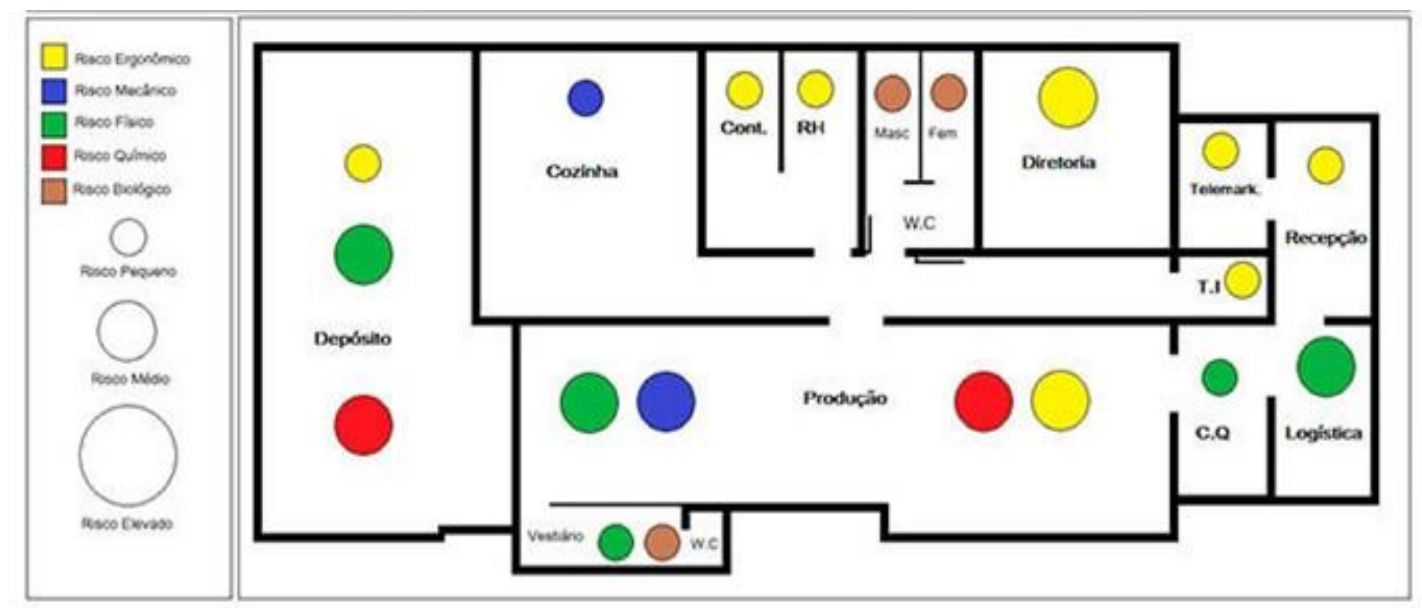

Figura 1 - Exemplo de Mapa de Risco

Foto: (Adaptado de CASTRO, 2019).

A construção do mapa deve seguir as seguintes etapas (NUNES, 2020):

1. Conhecer o processo de trabalho: perfil dos trabalhadores, quantidade, sexo, idade, treinamentos feitos;

2. Identificação dos riscos existentes no local: os riscos podem ser químicos (vermelho), físicos (verde), biológicos (marrom/amarelo escuro), ergonômicos (amarelo), mecânicos ou de acidente (azul).

3. Identificação das medidas preventivas existentes: são as medidas de proteção coletiva, individual, de organização do trabalho e de higiene.

4. Identificar os indicadores de saúde: verificar quais são as queixas mais comuns entre os trabalhadores, qual grupo está exposto ao mesmo tipo de risco, se já ocorreram acidentes no local e quais as doenças ocupacionais relacionadas à atividade.

A portaria $n^{\circ}$ 25/94, que instituiu o mapa de riscos, descreve que a CIPA deve discutir e aprovar o mapa, seja ele completo ou setorial. Além disso, ele deve ser afixado em local visível no setor que foi analisado, devendo ser de fácil acesso dos trabalhadores. O não cumprimento dessas medidas pode acarretar em multa. (CAMISASSA, 2021).

Para Campos et. al. (2020), o mapeamento ajuda a criar uma atitude mais cautelosa por parte dos trabalhadores diante dos perigos identificados e graficamente 
sinalizados. Desse modo, contribui para a eliminação ou controle dos riscos detectados. As informações mapeadas são de grande interesse com vista à manutenção e ao aumento da competitividade, prejudicada pela descontinuidade da produção interrompida por acidentes. Também permite a identificação de pontos vulneráveis na sua planta.

\subsection{Princípios da NR-10}

A NR-10 teve sua primeira redação publicada e aprovada pela Portaria no 3.214, de 1978, porém, a Portaria o 598 de 2004 trouxe diversas modificações no texto original. Segundo Pereira e Sousa (2020), esta norma aplica regras de conduta e procedimentos para atividades relacionadas a instalações elétricas.

O novo texto se fez necessário porque, no Brasil, a grande quantidade de privatizações no setor elétrico caminhou para um novo modelo de gestão, onde os trabalhadores são exigidos com metas de produtividade e eficiência cada vez mais altas. Além disso, o desenvolvimento de novas tecnologias e materiais, reestruturação dos processos produtivos e aumento de terceirizações, aumentaram a exposição do trabalhador a riscos. (LOURENÇO, LOBAO, 2018).

Esta Norma Regulamentadora - NR tem requisitos e mínimas condições com objetivo a implementar medidas de controle e sistemas preventivos para a garantia da segurança e saúde dos trabalhadores que interajam diretamente ou indiretamente em instalações elétricas e serviços com eletricidade. (NR-10)

Esta mudança na redação da norma começa com uma afirmação bem clara de que ela irá tratar dos requisitos e condições mínimas, que devem ser atendidos para qualquer trabalho que envolva eletricidade, a intenção é que o trabalhador tenha mais segurança e salubridade (PEREIRA, SOUSA, 2017).

Já para Fernandes (2017), a nova norma apresentou o conceito de gestão e organização do trabalho, através de abordagens como o Ciclo PDCA (Plan, Do, Check, Act). Além disso, torna necessário o uso de prontuários, EPI's, EPC's, treinamentos, autorizações. Essas mudanças têm como objetivo a melhoria contínua nos processos de trabalho.

As principais alterações na norma foram (LOBAO, LOURENÇO, 2018):

I. Estabelece regras mínimas para medidas que visem prevenir risco elétrico. 
II. As empresas são obrigadas a atualizar seus esquemas unifilares nas instalações elétricas. No caso de haver carga superior a $75 \mathrm{KW}$, é obrigatório o uso do prontuário com todos os registros, dentro das medidas de proteção individual e coletiva;

III. Realizar relatório de auditoria de conformidade das instalações elétricas;

IV. Torna obrigatória a introdução de dispositivos e equipamentos e medidas de controle coletivo;

V. Faz referência a NR-6 para implementar medidas de proteção individual, todavia, prevê a exigência o uso de vestimentas adequadas ao trabalho não prescritas na referida norma, bem como, proíbe o uso de adornos pessoais;

VI. Obrigatoriedade de introduzir conceitos de segurança no projeto das instalações elétricas;

Pode-se dizer que este novo texto faz uma inserção de conceitos e regras, que antes não eram observados pelas empresas. A nova norma ressalta a necessidade de serem feitos planejamentos quanto aos serviços, aos riscos e à adequação a cada tipo de trabalho (PEREIRA, SOUSA, 2017).

Para Lobão e Lourenco (2017), essa nova visão que a norma trouxe evidencia a necessidade de se aplicar medidas realmente eficazes quanto à segurança, individual e coletiva. Essas medidas de segurança foram divididas em cinco grupos: controle de risco, proteção coletiva, sinalização de segurança, proteção individual e responsabilidades.

Mediante uma análise de risco elétrico, devem ser adotadas medidas preventivas em todas as intervenções em instalação elétrica, de forma a garantir a segurança e a saúde do trabalhador. (NR-10)

Essas medidas de controle têm por objetivo eliminar ou reduzir todos os riscos inerentes à atividade em eletricidade, através de ações estratégicas preventivas. Elas devem ser muito bem planejadas e implementadas, pois são a bases para toda a segurança no trabalho. (CUNHA, 2018; LOBÃO, LOURENÇO, 2017; PEREIRA, SOUSA, 2020).

Camisassa (2019) reforça que o item 10.2.1 demonstra a necessidade de se estabelecerem medidas através de uma atitude proativa, promovendo a educação 
(treinamentos/atualizações) e conscientização que levem o trabalhador a ser capaz de verificar o risco ao qual está exposto, avaliá-lo e estabelecer medidas de contenção.

Já para Cunha (2018), cabe também aos responsáveis pela execução do serviço em instalações elétricas, sejam empregados diretos ou terceirizados, avaliar os riscos contidos na execução do serviço. Somente assim, será possível estabelecer as medidas de prevenção mínimas para evitar os acidentes com eletricidade.

O autor ressalta que esse não é apenas uma exigência legal, mas, mais do que isso, é um dever moral. Afinal, essa atitude garante também a segurança de outras pessoas, que eventualmente venham a sentir as consequências da incompetência empresarial. (CUNHA, 2021)

Pereira e Sousa (2017) complementam ao dizer que este item determina a necessidade de se fazer uma Análise de Riscos, que consistem em um método de identificação do risco, enquadramento do nível de exposição do trabalhador e aplicação de medidas de controle.

É, portanto, uma ferramenta de exame crítico da atividade ou situação, com grande utilidade para a identificação e antecipação dos eventos indesejáveis e acidentes possíveis de ocorrência. Isso possibilita a adoção de medidas preventivas de segurança e de saúde do trabalhador, do usuário e de terceiros, do meio ambiente e até mesmo evitar danos aos equipamentos e interrupção dos processos produtivos. (CUNHA, 2021).

Quanto a proteção coletiva, prioritariamente devem ser previstas e dotadas medidas de proteção coletiva mediante procedimentos as atividades a serem desenvolvidas em todos os serviços executados de forma a garantir a saúde e segurança de todos profissionais envolvidos. (NR-10)

Essas são medidas que devem ser tomadas quando os riscos estão no mesmo grau de exposição para todos os trabalhadores, buscando sempre prevenir os acidentes dos envolvidos na atividade, direta ou indiretamente. (LOBÃO, LOURENÇO, 2017; CUNHA, 2018).

Segundo Bonilha (2017), esta medida também deve ser planejada e implementada mediante a Análise de Risco, é importante que seja elaborado um documento e divulgado para todos os trabalhadores envolvidos.

Camisassa (2019) ressalta ainda que este item exige a proteção, inclusive, de pessoas que não estão relacionadas à execução do serviço, mas apenas transitando 
pelo local e que, portanto, também estão sujeitos aos riscos da atividade desenvolvida.

O termo grifado, prioritariamente, sinaliza que essas ações de prevenção devem ser executadas em ordem de preferência, sendo que as medidas de proteção coletiva estão em um nível maior de importância, devendo ser antecipadas a todas as demais medidas de proteção (CUNHA, 2021).

Para o cumprimento desta medida faz-se necessário o uso de Equipamentos de Proteção Coletiva (EPC), que são utilizados para a proteção de grupos de trabalhadores em relação aos riscos existentes. (LOBÃO, LOURENÇO, 2017).

Também se destacam as seguintes medidas para liberação do trabalho em áreas desenergizadas (art. 10.5.1): seccionamento, impossibilidade de reenergização, ausência de tensão elétrica, aterramento do equipamento, instalação de aterramento temporário com equipotencialização dos condutores dos circuitos, proteção dos elementos energizados existentes na zona controlada e equipotencialização. (NUNES, 2020).

Além disso, como ressaltado por Cunha (2018), a NR0-10 destaca o uso de isolamentos, bloqueios, delimitações de áreas, sinalização e aterramento. O bloqueio ou barreira é considerado uma proteção total; o obstáculo ou isolamento, que é considerado uma proteção parcial, é uma medida de proteção somente para as pessoas que tem conhecimentos dos riscos que a eletricidade pode oferecer, no âmbito da NR-10, para os trabalhadores autorizados.

Segundo Bonilha (2017), os EPC mais utilizados são:

- Vara de manobra isolada

- Conjunto de aterramento temporário

- Detector de tensão

- Cones e bandeirolas de sinalização

- Escadas com isolamento próprias para trabalho com eletricidade

Por fim, é fundamental ressaltar que a execução de serviços em instalações elétricas, para ser feita de forma segura, depende fundamentalmente da "desernegização" dos equipamentos. Quando isso não for possível, a NR-10 recomenda a utilização de tensão abaixo de 50v, chamada de tensão de segurança (NUNES, 2020). 
No caso de trabalhos em instalações elétricas que tecnicamente a proteção coletiva forem inviáveis ou insuficientes na questão de controle de riscos para as atividades desenvolvidas devem ser adotados o uso de equipamentos de proteção individuais, como disposto na NR 6. (NR-10)

Essas medidas devem ser utilizadas tão somente quando a proteção coletiva não for suficiente para manter o trabalhador isolado do risco da atividade. Sua principal característica é o uso do Equipamento de Proteção Individual (EPI), que são recursos disponibilizados para os trabalhadores utilizarem individualmente. (LOBÃO e LOURENÇO, 2017).

Os EPI's mais utilizados são:

- Capacete de segurança com isolamento para eletricidade

- Meia bota isolada

- Óculos de segurança incolor e com proteção contra raios ultravioletas

- Roupas de algodão

- Luvas de borracha isolantes BT e AT

- Luvas de pelica para proteção das luvas de borracha

- Luvas de raspa para trabalhos rústicos

- Cinturão de segurança com talabarte para trabalhos em grandes alturas

Em relação às luvas de borracha, deve-se seguir o seguinte sistema de classificação (NUNES, 2020):

\begin{tabular}{|c|c|}
\hline CLASSE & $\begin{array}{c}\text { TENSÃO DA CORRENTE } \\
\text { ALTERNADA }\end{array}$ \\
\hline 0 & 1.000 \\
\hline 1 & 7.500 \\
\hline 2 & 17.500 \\
\hline 3 & 26.500 \\
\hline 4 & 36.000 \\
\hline
\end{tabular}


Nos procedimentos do trabalho na segurança em projetos, é imprescindível que os projetos de instalações elétricas tenham detalhamento especificando os dispositivos de desligamento de circuitos que tenham recursos de impedimento de reenergização para sinalizar advertindo as indicações da condição operativa. (NR-10)

O parágrafo anterior e seguinte são os que apresentam as maiores inovações no texto atualizado da norma, principalmente por trazer à tona o conceito de antecipação dos riscos. Dessa forma, os trabalhos serão orientados já na fase inicial em relação aos potenciais riscos das instalações, sendo possível sua neutralização (CAMISASSA, 2019).

Para Pereira e Sousa (2020), ao chamar a atenção para os procedimentos, a nova norma demonstra que há a necessidade de a empresa desenvolver uma política de segurança, envolvendo planejamento e controle das medidas de proteção.

Cunha (2018) complementa ao dizer que a segurança em instalações elétricas deve ser uma preocupação constante, desde os estudos e análises iniciais, passando pela implementação e concretização do projeto.

A nova norma, no seu item 10.2.8.2, ressalta a importância do controle de desenergização como primeira medida de controle nas intervenções em instalações elétricas. É considerada desernegizada uma instalação que cumpre os requisitos contidos no item 10.5.1, com destaque para as alíneas $b$, que estabelece o impedimento de reenergização; e $f$, que estabelece a instalação da sinalização de impedimento de reenergização. (CUNHA, 2018).

Para permitir que o trabalhador possa realizar estas operações a NR-10 determinou que os projetos especificassem dispositivos que permitam a realização do impedimento de reenergização, também conhecido como bloqueio, e a sinalização do impedimento. (PEREIRA, SOUSA, 2017; CUNHA, 2018; LOBÃO, LOURENÇO, 2017).

\subsection{Importância do planejamento e análise dos riscos}

O planejamento dos riscos é uma forma de verificar a existência de possíveis acidentes de trabalho ao realizar atividades em instalações elétricas, ele também auxiliar na quantificação das consequências dos riscos. (LOBÃO, LOURENÇO, 2018). 
Para Campos et. al. (2020), os riscos podem ser calculados da seguinte forma:

$$
R I S C O=F R E Q U \hat{E} N C I A \times G R A V I D A D E
$$

Onde a frequência representa uma quantidade de acidentes e a gravidade é 0 grau de intensidade dos danos causados por cada acidente.

A principal vantagem do planejamento é o fornecimento de elementos para tomadas de decisões que envolvam confiança e segurança, possibilitando assim, apresentar alternativas claras e objetivas para o gerenciamento dos riscos. (LOBÃO e LOURENÇO, 2018; CAMPOS et. al. 2020).

Cunha (2019) e Bonilha (2017), complementam ao dizer que para gerenciar riscos é necessário formar uma nova ótica no conceito de segurança do trabalho, tanto no aspecto de prevenção como no aspecto da ação. Nessa nova visão, o foco está na busca pelas causas primárias, ou seja, os fatos geradores de acidentes.

A NR-9 institui o PPRA como modelo para o gerenciamento efetivo e total dos riscos ambientais. No setor elétrico é muito comum as empresas utilizarem a Análise Preliminar de Risco - APR, que de certa forma tem o mesmo principio e objetivo do PPRA, ou seja, a previsão da ocorrência danos para as pessoas, processos, equipamentos e meio ambiente, no exercício de determinada atividade. (BRASIL, 2004; LOBAO e LOURENÇO, 2018).

\section{METODOLOGIA}

A figura 2 apresenta o fluxograma da metodologia utilizada para a elaboração deste trabalho.

O trabalho foi desenvolvido a partir de pesquisa bibliográfica. A pesquisa bibliográfica foi efetuada através da internet e biblioteca. $\mathrm{Na}$ internet foram consultados os sites do MTE. 


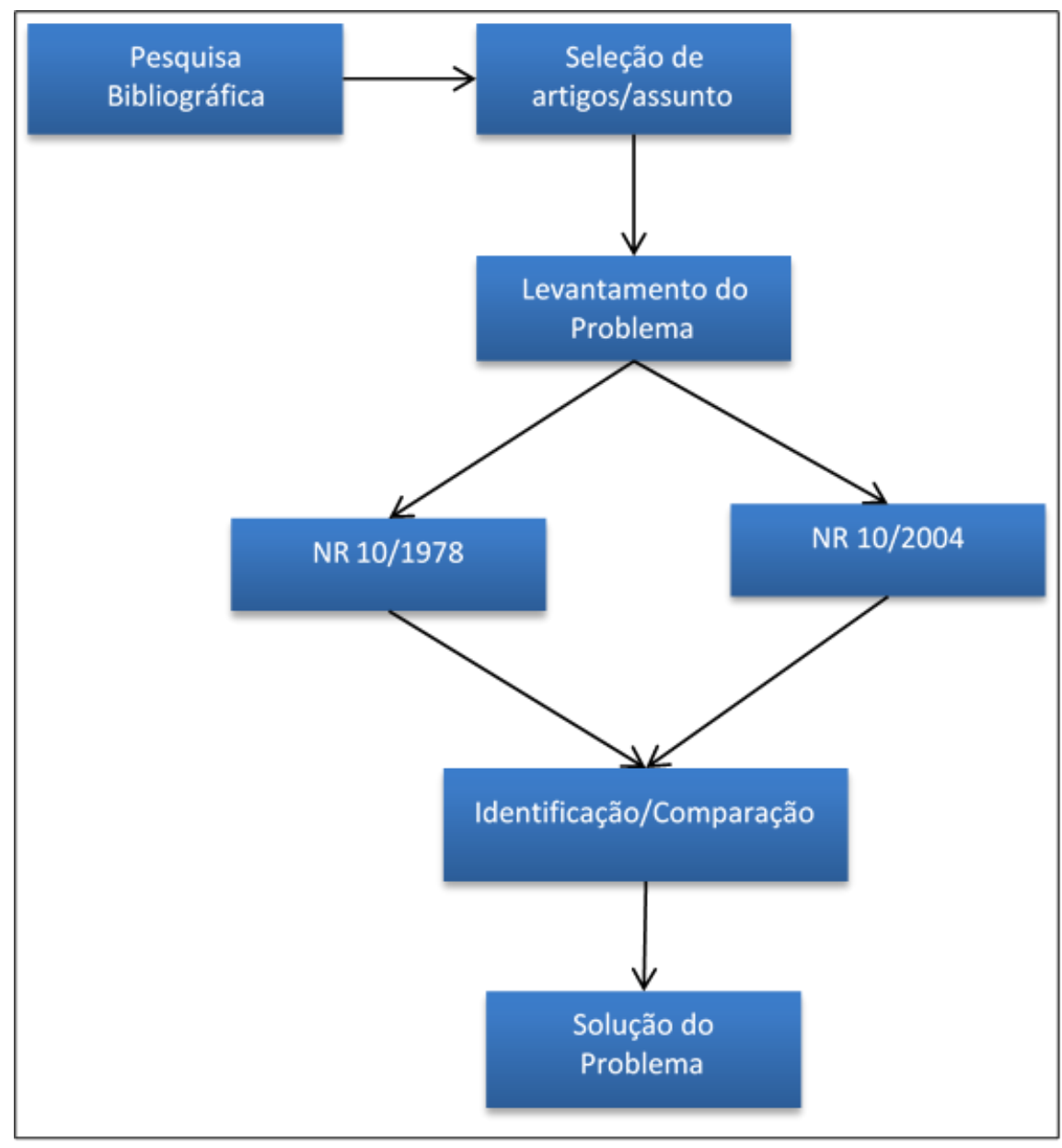

Figura 2 - Metodologia Utilizada

Foto: (Elaborado pelo autor, 2021).

\section{RESULTADOS}

Dentre os resultados encontrados nesta pesquisa, destaca-se a identificação de semelhanças e diferenças entre o primeiro texto da NR-10, do ano de 1978, e sua atualização em 2004.

O novo texto exige a elaboração de relatórios técnicos das instalações, bem como o Prontuário de Instalações Elétricas (PIE), que é um sistema de organização das informações relevantes para a execução dos trabalhos em instalações elétricas. Ele reúne os procedimentos, ações e documentos que objetivam proteger o trabalhador quando está exposto a riscos elétricos.

Também surgiu a visão de gestão e planejamento de projetos, com objetivo de prevenir e organizar os trabalhos nas instalações. Isso deve ser feito a partir do chamado "ciclo PDCA", planejar, fazer, checar, agir. 
Em resumo, pode-se dizer que a nova norma exige um método de trabalho mais amplo, não apenas focado na execução do serviço, mas com uma visão total do que será executado; prevenindo e minimizando riscos, não só dos trabalhadores, mas de todas as pessoas que podem ser atingidas por choques elétricos. (GUIA TRABALHISTA, 202)

A nova norma também ampliou as exigências quanto às responsabilidades dos trabalhadores e dos empregadores envolvidos em serviços com eletricidade.

Antes, o cumprimento da norma era de responsabilidade apenas do profissional qualificado, que tinha autorização para trabalhar com instalações elétricas. No novo texto, as responsabilidades são dividas: os empregadores, ou contratantes, devem informar os trabalhadores quanto aos riscos, procedimentos e medidas de controle.

Já aos trabalhadores cabe:

a) Cuidar da sua saúde, mental e física, além de se atentar para a segurança de outras pessoas que venham a sofrer com suas ações inadequadas.

b) Cumprir, junto com a empresa, todas as exigências legais e regulamentares, incluindo os procedimentos internos que garantam segurança e saúde no trabalho;

c) Comunicar imediatamente o responsável pelo serviço sobre a(s) situação(ões) que podem gerar algum risco para segurança e saúde individual e/ou coletiva.

No entanto, apesar das alterações feitas, os serviços em instalações elétricas são executados, infelizmente, sem a correta aplicação da norma NR-10, ainda há um grande número de trabalhadores que desconhecem ou ignoram tais recomendações.

O não cumprimento da NR-10 aumenta muito as chances de ocorrerem acidentes de trabalho e quando se fala em instalações elétricas, o choque elétrico pode ser fatal.

Acredita-se que isso ocorra em virtude da falta de esclarecimentos dos procedimentos exigidos, onde os trabalhadores não sentem necessidade de aprender sobre a NR-10. Existem dificuldades em entendê-la, por ser extensa e complexa.

Portanto, há necessidade de se elaborar um documento, como um check-list, para que esses trabalhadores tenham maior facilidade em executar as ações de segurança.

Através da utilização do método de causa-raiz, também chamado de " 5 por quês" fica mais fácil o entendimento sobre a necessidade do check-list: 
1) Por que ocorrem acidentes em instalações elétricas? Não há aplicação da norma.

2) Por que a norma não é aplicada corretamente? Os trabalhadores não a entendem.

3) Por que os trabalhadores não a entendem? Porque ela é extensa e complexa.

Com o intuito de reduzir a taxa de não utilização e aplicação da norma, bem como aumentar o grau de compreensão da mesma, este trabalho se propôs a elaborar um documento que servirá como roteiro para a execução de trabalhos em instalações elétricas (o modelo está apresentado no Anexo 3).

Este documento-modelo foi elaborado com base nos resultados obtidos por meio da revisão de literatura de diversos autores, bem como através da análise das duas versões da norma.

Ele busca abordar, de forma clara e simples, todos os grupos temáticos contidos no novo texto da NR-10: medidas de controle, proteção individual, proteção coletiva, segurança em projetos e segurança na construção, montagem, operação e manutenção.

\section{CONSIDERAÇÕES FINAIS}

É fundamental que as leis sejam reescritas, ampliadas e aperfeiçoadas, de modo que consigam se adequar aos novos modelos sociais, organizacionais, culturais e de trabalho. Assim, quando surgem fatos e situações não previstos na legislação, a sociedade ou o grupo ao qual a lei se destina, não tem um direcionamento.

Quando se fala em legislação trabalhista, é imprescindível que os textos sejam adequados, pois o mercado de trabalho e, principalmente, as empresas, estão constantemente se modificando e se transformando. Consequentemente, os trabalhadores passam a ser mais exigidos por seus contratantes, para que executem as atividades da melhor forma possível.

Nesse sentido, uma norma regulamentadora é um instrumento que estabelece as diretrizes de trabalho, que tem o objetivo primário de proteger a pessoa do trabalhador, sua saúde física e mental, bem como determinar a forma com que o serviço será executado, garantindo eficiência e segurança. 
O objetivo principal deste trabalho foi analisar as mudanças ocorridas na NR10 "Segurança em Instalações e Serviços em Eletricidade", comparando as versões de 1978 e 2004. E, a partir disso, elaborar um documento que se preste a facilitar a aplicação da norma, tendo em vista que foi identificada uma dificuldade dos trabalhadores em fazê-lo.

O documento contém todos os eixos temáticos do novo texto, numa abordagem clara, direta e simplificada, podendo ser utilizado por todo trabalhador que sinta necessidade de aperfeiçoar seu serviço em eletricidade.

Como resultado, espera-se que os riscos de acidente de trabalho em instalações elétricas sejam minimizados ao máximo.

\section{REFERÊNCIAS}

PREVIDENCIA - Acidente de trabalho - NR-10 - Disponível em:

https://protecao.com.br/estatisticas/previdencia-social-divulga-as-ultimas-estatisticasde-acidentes-de-trabalho-no-pais/ >Acesso em 09 set. 2020

BARROS, B. F. de. NR 10, guia prático de análise e aplicação comentado. $8^{a} \mathrm{ed}$. Campinas: Atlas, 2020.

BONILHA, J. E. A segurança do trabalhador: uma preocupação constante. Revista Eletrônica FTEC, v. 1, 2017. Disponível em:

http://junior.ftec.com.br/revista/autor/pdf/josebonilla.pdf >Acesso em 09 set. 2020.

NORMAS - BRASIL, Ministério do Trabalho e Emprego - MTE. Norma

Regulamentadora no 10 - NR 10: Segurança em instalações e serviços em eletricidade. Brasília: MTE, 2004. Disponível em:

http://portal.mte.gov.br/data/files/8A7C812D308E216601310641F67629F4/nr 10.pdf >Acesso em 20 set. 2020.

NORMAS - NR-10 - Disponível em:

https://clinimedjoinville.com.br/o-que-e-a-nr-10-seguranca-em-instalacoes-eservicos-em-eletricidade/ >Acesso em 20 set. 2020.

, Portaria oㅡ 25 de 29 de dezembro de 1994. Brasília: MTE, 1994.

Disponível em:

http://portal.mte.gov.br/data/files/FF8080812BE914E6012BEA44A24704C6/p 19941 $\underline{229} 25 . \mathrm{pdf}>$ Acesso em 20 set. 2020. 
, Norma Regulamentadora ํo 5 - NR 5: Comissão Interna de

Prevenção de Acidentes. Brasília, MTE, 1978. Disponível em:

http://portal.mte.gov.br/data/files/8A7C812D311909DC0131678641482340/nr 05.pdf

>Acesso em 20 set. 2020.

, Norma Regulamentadora no 9 - NR 9: Programa de Prevenção de

Riscos Ambientais. Brasília, MTE, 1978. Disponível em:

http://portal.mte.gov.br/data/files/8A7C812D311909DC0131678641482340/nr 05.pdf

>Acesso em 20 set. 2020 .

NR-10 - Legislação - Disponível em:

http://www.guiatrabalhista.com.br/legislacao/nr/nr10.htm\#: :text=10.1.1\%20Esta\%20 Norma\%20Regulamentadora, el\%C3\%A9tricas\%20e\%20servi\%C3\%A7os\%20com\% 20eletricidade. $>$ Acesso em 20 set. 2020.

CAMISASSA, M. Q. Segurança e saúde no trabalho: NR'S 1 A 37. 6ª ed. São Paulo: Saraiva, 2019. > Acesso em 20 set. 2020

CAMPOS, A. CIPA - Comissão Interna de Prevenção de Acidentes: uma nova abordagem. 20aㅡ ed. São Paulo: SENAC, 2020. > Acesso em 20 set. 2020

CAMPOS, A. et. al. Prevenção e controle de risco em máquinas e equipamentos e instalações. 6ª ed. São Paulo: SENAC, 2019. > Acesso em 20 set. 2020

COPEL - Companhia Paranaense de Energia. Guia de segurança nas instalações elétricas. Curitiba: COPEL, 2017. Disponível em:

http://www.copel.com/hpcopel/root/sitearquivos2.nsf/arquivos/dicas de seguranca n as instalacoes eletricas/\$FILE/pdf seguranca.pdf $>$ Acesso em 10 set. 2020.

CUNHA - Ações de prevenção - NR10 - Disponível em: CUNHA, J. G. Norma Regulamentadora nำ10 comentada. São Paulo: MiOmega, 2018. > Acesso em 10 set. 2020

CASTRO, S. de. Mapa de riscos: explanação completa. 2019. Disponível em: http://santosde.blogspot.com.br/2019/10/mapa-de-riscos 16.html>Acesso em 17 set. 2020.

DUL, J.; WEERDMEESTER, B. Ergonomia prática. 6 $6^{\underline{a}}$ ed. Rio de Janeiro: Blucher, 2019. > Acesso em 17 set. 2020 GUIA TRABALHISTA - Nova Norma - NR10 - Disponível em: http://www.guiatrabalhista.com.br/legislacao/nr/nr10.htm > Acesso em 17 set. 2020 
FERNANDES, A. C. A Nova Norma Regulamentadora n 10. 2017. Revista Brasil Engenharia. Disponível em

http://www.brasilengenharia.com/portal/images/stories/revistas/edicao582/110Eletric a582.pdf $>$ Acesso em 09 set. 2020.

NR10 - Disponível em: GIL, A. C. Como elaborar projetos de pesquisa. $4^{a}$ ed. São Paulo: Atlas, 2017. >Acesso em 09 set. 2020.

LOURENÇO, H; LOBÃO, E. Análise de segurança do trabalho em serviços com a eletricidade sob a ótica da nova NR 10. 2017. Disponível em. http://www.dalmoro.com.br/images/publications/original/08042017161015.pdf >Acesso em 03 set. 2020.

Segurança no trabalho: análise das alterações propostas na revisão da NR 10. Seminário Internacional de Arquitetura e Urbanismo. 2018. Disponível em: http://www.dalmoro.com.br/images/publications/original/08042017161136.pdf >Acesso em 05 set. 2020 .

MAHLE. Trabalho com eletricidade: procedimentos de segurança e saúde ocupacional. São Paulo: MAHLE, 2018. Disponível em: http://www.mahle.com.br/C1256F7900537A47/vwContentByKey/W289ZQHU121STU LEN/\$FILE/Trabalho\%20com\%20Eletricidade.pdf >Acesso em 10 set. 2020.

NUNES, F. O. Segurança e saúde no trabalho esquematizada: NR-10. São Paulo: Campos Elsevier, 2019. >Acesso em 10 set. 2020.

SENAI, Serviço Nacional de Aprendizagem Industrial. NR 10: segurança em instalações e serviços em eletricidade: Reciclagem. $2^{\mathrm{a}}$ ed. São Paulo: Editora SENAI, 2018. >Acesso em 10 set. 2020.

PEREIRA, J. G; SOUSA, J. J. B. Manual de auxílio na interpretação e aplicação da NR-10. $2^{\underline{a}}$ ed. Brasília. Ministério do Trabalho e Emprego, 2020. >Acesso em 10 set. 2020.

VILLAIN, F. S. Segurança em eletricidade: proposta de implantação da nova NR-10. [tese] Universidade Extremo-sul Catarinense. Criciúma, 2017. >Acesso em 10 set. 2020.

ZOCCHIO, A. Prática da Prevenção de acidentes: ABC da segurança do trabalho. $7^{a}$ ed. São Paulo: Atlas, 2016. >Acesso em 10 set. 2020. 